\title{
Spermatogenic and sperm quality differences in an experimental model of metabolic syndrome and hypogonadal hypogonadism
}

\author{
Con Mallidis ${ }^{1,2}$, Agnieszka Czerwiec ${ }^{2}$, Sandra Filippi ${ }^{3}$, Jason $\mathrm{O}^{\prime} \mathrm{Neill}^{2}$, Mario Maggi ${ }^{3}$ \\ and Neil McClure ${ }^{2}$ \\ ${ }^{1}$ Centre of Reproductive Medicine and Andrology, University of Münster, Domagkstrasse 11, D-48149 Munster, \\ Germany, ${ }^{2}$ Department of Obstetrics and Gynaecology, Queen's University Belfast, Belfast, BT12 6BJ, UK and \\ ${ }^{3}$ Andrology and Sexual Medicine Unit, Department of Clinical Physiopathology, University of Florence, \\ Florence 50139, Italy \\ Correspondence should be addressed to C Mallidis at Centre of Reproductive Medicine and Andrology, University of Münster; \\ Email:con.mallidis@ukmuenster.de
}

\begin{abstract}
The synergistic effect of the co-morbidities that comprise metabolic syndrome (MetS) is increasingly being recognised as an important contributor in the pathology of a broad spectrum of seemingly disparate conditions. However, in terms of male reproductive function, beyond erectile dysfunction, little is known about the influence of this cohort (collectively or separately) on spermatogenesis and sperm quality. The aims of this study were to assess the reproductive tract of a MetS animal model for detrimental changes, to determine whether a group of compounds (advanced glycation end products and their receptor) known to cause cell dysfunction and DNA damage was present and assess whether hypogonadotropic hypogonadism was the main contributing factor for the changes seen. Animals fed a high-fat diet were found to have significantly increased cholesterol, triglycerides, blood glucose, mean arterial pressure and visceral fat levels. Although serum testosterone was decreased, no changes were seen in either testicular or epididymal histology. Immunolocalisation of $\boldsymbol{N}^{\varepsilon}$-carboxymethyl-lysine and the receptor for advanced glycation end products was found in the testes, epididymides and sperm of the two treated groups of animals; however, ELISA did not show any difference in protein levels. Similarly, assessment of sperm nuclear DNA (nDNA) fragmentation by acridine orange test did not find significant differences in nDNA integrity. We conclude that the minimal effect on spermatogenesis and sperm quality seen in our model is probably due to the moderate increase of blood glucose rather than the hypogonadism.

Reproduction (2011) 142 63-71
\end{abstract}

\section{Introduction}

In response to the more than tripling in prevalence over the last 30 years, the American Heart Association in its recent research summit report (Daniels et al. 2009) concluded that childhood and adolescent obesity constitutes a crisis of such magnitude that it necessitates immediate intervention by the health care community. A worldwide problem, this burgeoning epidemic (reviewed by Ben-Sefer et al. (2009)), currently affects between 10 and $30 \%$ of children and adolescents and is accompanied by higher incidences of insulin resistance, hypertension and dyslipidemia (Daniels et al. 2009). Together, this cohort of conditions comprises the basis for the metabolic syndrome (MetS).

Although the precise definition of the syndrome still remains contentious, with differing criteria being proposed by differing organisations (Cornier et al. 2008), there is no disagreement on the deleterious associations and consequences of the co-morbidities. Among others, cardiovascular disease, atherosclerosis, non-alcoholic liver disease, polycystic ovarian syndrome, chronic inflammation and schizophrenia have all been linked to MetS (Meyer et al. 2005, Cornier et al. 2008). The increasing number of patients being diagnosed prior to and/or during their reproductive years coincides with the reports linking various elements of the syndrome with decreased fecundity. In the male, studies by Ramlau-Hansen et al. (2007) and Nguyen et al. (2007) concluded obesity to be associated with a $20 \%$ greater likelihood of subfertility or infertility, respectively, whereas a large epidemiological study by Sallmen et al. (2006) concluded that a $10 \mathrm{~kg}$ increase in weight was sufficient to decrease male fertility by as much as $10 \%$.

Although associations of MetS with heightened risks of gonadal (i.e. hypogonadism) and erectile dysfunction are noted and widely acknowledged (Corona et al. 2009), the existing evidence for the possible influence of the syndrome's co-morbidities on spermatogenesis is somewhat confusing. Jensen et al. (2004) found significant decreases in total sperm count in young overweight 
(i.e. body mass index $(\mathrm{BMI})>25 \mathrm{~kg} / \mathrm{m}^{2}$ ) army conscripts, a finding corroborated in part by Kort et al. (2006) who reported a significant inverse relationship between BMI and total normal motile sperm. However, Chavarro et al. (2009), found the decrease in total sperm count to be present only in the extremely obese (i.e. BMI $>35 \mathrm{~kg} / \mathrm{m}^{2}$ ). Confusingly, Hammoud et al. (2008b) initially reported that the incidence of oligo- and asthenozoospermia increased with increasing $\mathrm{BMI}$, a finding seemingly contradicted by a subsequent critical review of the literature by the same group (Hammoud et al. 2008a), which concluded that obesity had only a modest affect on male fertility. The latter view is supported by Aggerholm et al. (2008) who found that semen quality from men with a BMI between 25 and $30 \mathrm{~kg} / \mathrm{m}^{2}$ was only marginally decreased if at all and by MacDonald et al. (2010) who conducted a meta analysis of five published studies and concluded that there was little evidence of a relationship between $\mathrm{BMI}$ and semen quality. This disparity in concordance is reminiscent of studies on another co-morbidity of MetS, that of diabetes, where results on the condition's influence on sperm quantity and quality are also conflicting and inconclusive (Handelsman et al. 1985, Vignon et al. 1991, Niven et al. 1995). Interestingly, both conditions have been linked with a sperm abnormality that is independent of conventional measures of semen quality, namely, increased levels of sperm nuclear DNA (nDNA) fragmentation (Kort et al. 2006, Agbaje et al. 2007, Chavarro et al. 2009).

Associated with decreased embryo quality and lower implantation rates (Morris et al. 2002, Henkel et al. 2003), sperm nDNA damage is currently thought to result from the attack by reactive oxygen species (ROS) encountered in the testis and during transit through, and storage in, the epididymis (Fouchecourt et al. 2000, Vernet et al. 2004). The precise mechanism that investigates the oxidative stress that causes the generation of ROS and subsequently leads to sperm DNA damage remains unknown.

Summarising the available evidence, Kasturi et al. (2008) proposed a MetS-male infertility paradigm where ROS are generated as by-products of obesity, dyslipidemia, increased C-reactive protein and inflammation. However, other than acknowledging the associations between these factors and oxidative stress, the process(es) by which these conditions initiate and maintain such a destructive environment were not specified in the proposed scheme.

Findings from our recent studies on the influence of diabetes on male reproductive function may provide possible clues to a hitherto unidentified aspect of the underlying mechanism. We identified high levels of $N^{\varepsilon}$-carboxymethyl-lysine $(\mathrm{CML})$, the most prominent advanced glycation end product (AGE; Mallidis et al. 2009) and its receptor (RAGE; Mallidis et al. 2007) in the testis, epididymis and sperm of diabetic men and mouse models alike ( $\mathrm{O}^{\prime} \mathrm{Neill}$ et al. 2009). As this group of compounds is known to cause cellular dysfunction, oxidative stress and DNA damage in various organs and in a variety of conditions (Vlassara \& Palace 2002), we hypothesise that they may also play an equally destructive role in the reproductive tract of diabetics and MetS patients and as such contribute to the sperm nDNA fragmentation seen in these men.

The aims of this study were to determine whether CML and RAGE are present in the reproductive tract of a wellcharacterised animal model of MetS, to identify their locations, compare levels of protein, assess sperm nDNA integrity and determine whether hypogonadotropic hypogonadism $(\mathrm{HH})$ is the main contributing factor for the changes seen.

\section{Results}

\section{Effect of HFD on rabbits}

Other than total body weight, animals on the high-fat diet (HFD) were found to have statistically significant changes in all measured physical parameters (Tables 1 and 2). Blood glucose, cholesterol, triglycerides, mean arterial pressure and visceral fat were all significantly elevated in the HFD animals compared with those of the controls and their pre-diet levels. Administration of GNRH analogue did not appear to influence the metabolic characteristics of the rabbits but, as expected, caused decreases in testosterone level and its corollaries,

Table 1 Metabolic characteristics of rabbits.

\begin{tabular}{|c|c|c|c|c|c|}
\hline Rabbits & Total body weight (g) & Blood glucose (g/l) & Cholesterol (mg/dl) & Triglycerides $(\mathrm{mg} / \mathrm{dl})$ & Testosterone $(\mathrm{nmol} / \mathrm{l})$ \\
\hline \multicolumn{6}{|l|}{ Control } \\
\hline Baseline & $3225 \pm 76$ & $1.09 \pm 0.15$ & $33.7 \pm 3.3$ & $91.2 \pm 9.4$ & $7.54 \pm 1.81$ \\
\hline Week 12 & $4002 \pm 159$ & $1.17 \pm 0.14$ & $31.9 \pm 4.3$ & $90.6 \pm 9.4$ & $7.12 \pm 1.13$ \\
\hline \multicolumn{6}{|l|}{ HFD } \\
\hline Baseline & $3163 \pm 69$ & $1.36 \pm 0.05$ & $45.5 \pm 3.1$ & $90.1 \pm 9.0$ & $7.23 \pm 1.70$ \\
\hline Week 12 & $3805 \pm 83$ & $1.99 \pm 0.15^{+, \S}$ & $1247 \pm 66.2^{\ddagger \text {, }}$ & $301 \pm 48.5^{+, \S}$ & $2.20 \pm 0.60^{*}$ \\
\hline \multicolumn{6}{|l|}{$\mathrm{HH}$} \\
\hline Baseline & $3330 \pm 111$ & $1.03 \pm 0.08$ & $33.3 \pm 4.1$ & $77 \pm 11$ & $6.10 \pm 0.90$ \\
\hline Week 12 & $4064 \pm 126$ & $1.24 \pm 0.13$ & $45.9 \pm 7.2$ & $146 \pm 35$ & $1.58 \pm 0.08^{*}$ \\
\hline
\end{tabular}

${ }^{*} P<0.05,{ }^{\dagger} P<0.01,{ }^{\ddagger} P<0.0001$ versus relative baseline values. ${ }^{\circledR} P<0.01,{ }^{9} P<0.0001$ versus control week 12 . Results were obtained from at least eight animals for each group and are expressed as means \pm S.E.M. 
Table 2 Organ weights and mean arterial pressure of rabbits after 12 weeks.

\begin{tabular}{lcccc}
\hline & & \multicolumn{3}{c}{ Weight } \\
\cline { 3 - 5 } & \multirow{3}{*}{$\begin{array}{c}\text { MAP } \\
\text { Rabbits }\end{array}$} & $\begin{array}{c}\text { Visceral } \\
\text { fat }(\mathrm{g})\end{array}$ & $\begin{array}{l}\text { Seminal } \\
\text { vesicles } \\
(\mathrm{mg})\end{array}$ & Testis $(\mathrm{g})$ \\
\hline Control & $93.4 \pm 4.8$ & $27.9 \pm 2.5$ & $879 \pm 98$ & $3.50 \pm 0.13$ \\
HFD & $131.5 \pm 5.4^{+}$ & $49.5 \pm 3.2^{\dagger}$ & $560 \pm 45^{*}$ & $3.10 \pm 0.12^{*}$ \\
HH & $85.4 \pm 6.8$ & $73.2 \pm 5.5^{+, \neq}$ & $337 \pm 61^{*}$ & $2.76 \pm 0.30^{*}$ \\
\hline
\end{tabular}

$* P<0.05,{ }^{\dagger} P<0.01$ versus control, ${ }^{\ddagger} P<0.05$ versus HFD. Results were obtained from at least eight animals for each group and are expressed as means \pm s.E.M.

seminal vesicle and testicular weights. These decreases were also found in the HFD animals. Furthermore, the $\mathrm{HH}$ animals were found to have a significant increase in visceral fat compared with both the control and the HFD fed animals.

\section{Histology}

The presence of all eight spermatogenic stages (Swierstra \& Foote 1965) and cell progression culminating in mature spermatids of the control animals demonstrated the completion of normal spermatogenic activity. No difference was found in the spermatogenic stages in the HFD animals, although the number of mature spermatozoa appeared to be lower (data not shown). The testes of the $\mathrm{HH}$ animals contained tubules with a small spermatogenic epithelium populated primarily by large degenerating spermatocytes. Some abnormal spermatogonia were present close to the basement membrane (data not shown). Although no tubule showing complete spermatogenesis was found, the luminal compartments of some tubules seem to contain released spermatozoa.

The epididymal sections from all animals showed normal morphology with the tubule luminal spaces filled with spermatozoa (data not shown).

\section{CML and RAGE}

Testes

CML immunoreactivity was seen in the cytoplasm of all cells present in the seminiferous epithelium in all samples from all experimental groups (Fig. 1A-C). The intensity of staining, which extended from the basal membrane into the luminal space, increased across the groups from that seen in control samples (the least; Fig. 1A), to $\mathrm{HH}$ (more; Fig. 1B) to HFD (the most; Fig. 1C). No nuclear staining was seen in the cells of the tubule compartment; however, the nuclei of cells of the interstitium (myoid, fibroblasts and Leydig) did show distinct immunoreactivity.

Other than a diffuse staining of the developing acrosome, no RAGE immunoreactivity was found in the seminiferous tubules or the surrounding testicular interstitial in the control animals (Fig. 2A). In the $\mathrm{HH}$ animals (Fig. 2B), an intense immunoreactivity was found in the enlarged and degenerating spermatocytes. In the HFD group, a diffuse staining was present in the cytoplasm of Sertoli cells, spermatocytes and spermatids but not the spermatogonia (Fig. 2C). The most prominent immunoreactivity was found in the developing acrosomal cap of the spermatids. A faint cytoplasmic staining was also evident where clusters of Leydig cells were present.

\section{Epididymis}

A slight CML immunoreactivity was detected in the interstitial regions of the initial segment of the epididymes in the control animals (Fig. 1D), primarily in the cytoplasms of the myoid cells surrounding the tubules. Little evidence of CML was seen in the tubule compartment. A similar pattern was seen in the caput, although there was an increased intensity in the immunofluorescent staining of the smooth muscle delineating the tubules (Fig. 1G).
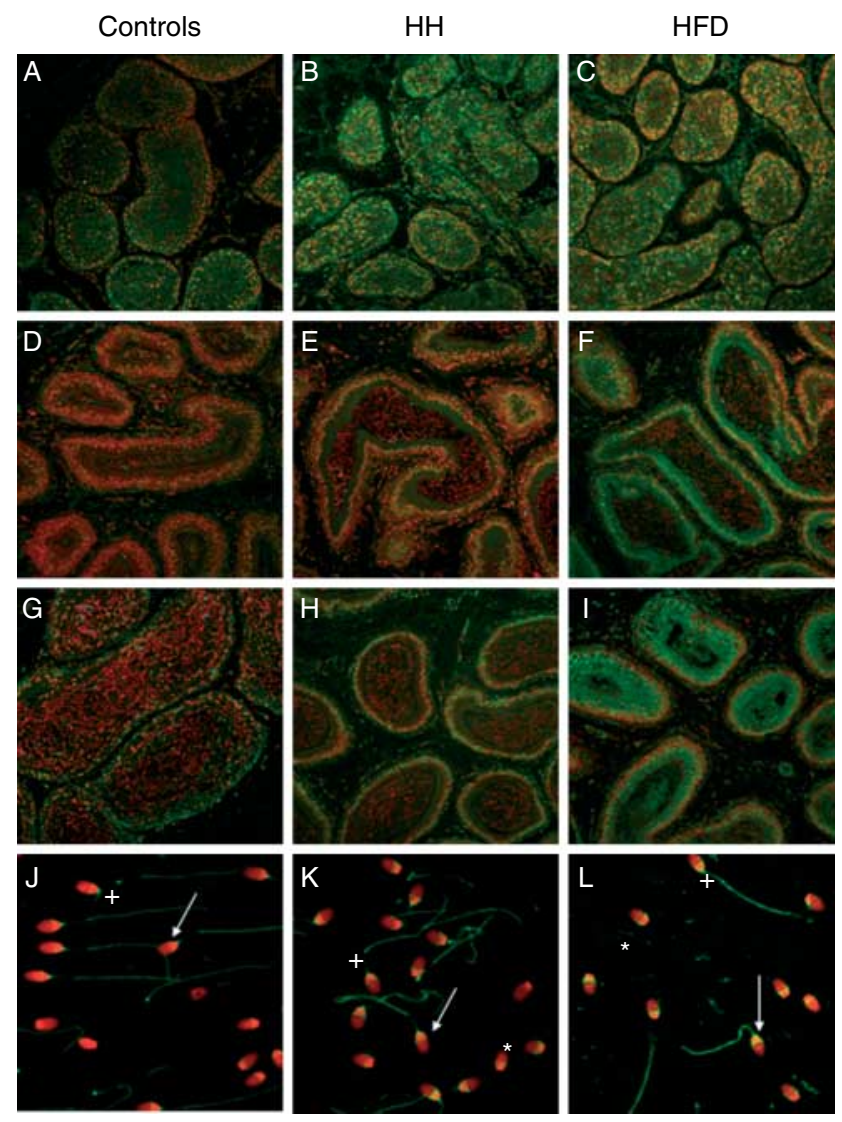

Figure $1 \mathrm{Immunolocalisation}$ of $N^{\varepsilon}$-carboxymethyl-lysine $(\mathrm{CML})$ in the testis (A-C), initial epididymal segment (D-F), caput epididymis $(G-I)$ and sperm $(\mathrm{J}-\mathrm{L})$ of control, hypogonadal hypogonadism $(\mathrm{HH})$ and highfat diet (HFD) rabbits. Variations in the staining of the head equatorial band and sperm mid piece are indicated by the arrow and cross respectively. The asterisk indicates sperm without tails. 

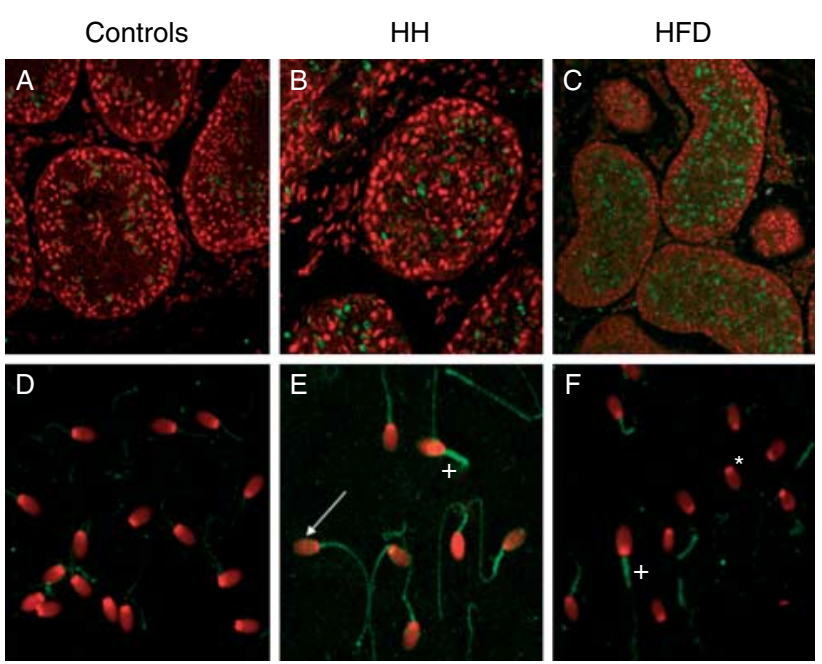

Figure 2 Immunolocalisation of the receptor for advanced glycation end products (RAGE) in the testis (A-C) and sperm (D-F) of control, hypogonadal hypogonadism $(\mathrm{HH})$ and high-fat diet (HFD) rabbits. The speckled staining of the acrosomal region of the sperm heads from $\mathrm{HH}$ animals is indicated by the arrow and the more intense immunoreactivity of sperm mid piece in both $\mathrm{HH}$ and HFD animals by the cross. The asterisk indicates sperm without tails.

Both epididymal regions of $\mathrm{HH}$ animals were found to have prominent staining of the principal cell nuclei with a distinct fluorescence being seen in the cytoplasm bordering the luminal space of the tubules (Fig. 1E and $\mathrm{H}$ ). The intensity of the nuclear staining was increased in the caput, while the cytoplasmic was noticeably diminished. Furthermore, a diffuse staining was present through out the entire interstitium of the caput with some regions of the outer dense connective tissue displaying strong immunofluorescence. A similar distribution of immunoreactivity was seen in the epididymes from HFD animals. However, in both regions, the intensity of staining was greater in the diet-fed group, particularly in the cytoplasm of the caput (Fig. 1F and I).

No RAGE immunoreactivity was seen in the initial segment or the caput of the epididymes of the control and HFD animals (data not shown). Only in the initial segment of the $\mathrm{HH}$ animals was a distinct speckled staining seen primarily in the apical region of the principal cells just below the extending stereocilia (data not shown).

\section{Sperm}

All samples from all animals showed a similar distribution of CML immunoreactivity, namely a speckled staining extending along the length of the tail (Fig. 1J-L). Sperm from $\mathrm{HH}$ and control animals showed little, if any, staining of the mid piece. This was in contrast to sperm from the HFD animals, which displayed clear CML immunoreactivity on the mid piece (Fig. 1L). The majority of sperm from all groups displayed prominent immunofluorescence on the head, in particular the equatorial band just below the acrosome. The intensity of immunofluorescence appeared to differ between the groups, with the least being seen in the control animals (Fig. 1J), a greater amount in the $\mathrm{HH}$ group (Fig. 1K) and the most in those on HFD (Fig. 1L).

Similar to the pattern seen for $\mathrm{CML}$, the tails of sperm from all groups showed speckled immunoreactivity for RAGE, which differed in intensity ranging from weak in the control animals (Fig. 2D), intermediate in the HFD group (Fig. 2F) and strong in the $\mathrm{HH}$ animals (Fig. 2E). In contrast to the observed CML immunodetection, numerous sperm of animals in the $\mathrm{HH}$ and HFD groups were found to have prominent staining of the mid piece region corresponding to the mitochondrial compartment. Furthermore, sperm from the $\mathrm{HH}$ animals showed a distinct speckled staining extending from the anterior edge of the head, an area approximating the acrosomal cap.

It should be noted that during the processing, a heightened degree of fragility in the tails was identified in all samples from the $\mathrm{HH}$ and HFD, whereby many separated heads were evident throughout the preparations of sperm from the analogue-treated animals (Figs $1 \mathrm{~K}$ and $2 \mathrm{E}$ ), whereas most of the sperm from the HFD were without tails (Figs $1 \mathrm{~L}$ and $2 \mathrm{~F}$ ).

\section{Protein quantitation and sperm nDNA damage}

The mean amount of CML in the sperm of the HFD and $\mathrm{HH}$ animals was greater than that found from the control animals (1.43-fold and 1.35 -fold respectively). Similarly, the percentage of sperm with nDNA fragmentation in the HFD animals was greater than the other groups (control: 1.30-fold and $\mathrm{HH}: 1.55$-fold). However, in both cases, the differences did not reach statistical significance (data not shown). Surprisingly despite the intensity of immunoreactivity seen on the sperm from HFD and $\mathrm{HH}$ animals, the level of RAGE in all samples from all the animals was below the detection limit of the assay (data not shown) and therefore no conclusion could be derived.

\section{Discussion}

Initially proposed as a possible indicator of the development of cardiovascular disease, the inference underlying the grouping of the various co-morbidities constituting MetS was, and remains, that the deleterious consequences of this combination are more than those resulting from the sum of the individual conditions alone. As such, MetS can be considered not as a disease per se but rather a pathway towards disease (Shabsigh et al. 2008), a juxtaposition of co-morbidities that exacerbate a pathological situation.

In terms of male reproductive function, the co-morbidities individually and collectively have been shown to be associated with erectile dysfunction 
(Corona et al. 2009), ejaculatory disturbances (Gould et al. 2006) and decreased testosterone levels (Kasturi et al. 2008). However, there are also reports of perturbations that are solely associated with certain conditions such as decreases in LH and FSH that have been found in models of hypertension (Breigeiron et al. 2007), dyslipidemia (Yamamoto et al. 1999) and obese humans (Sharpe 2010). Interestingly, our animal model of overall MetS displays all these facets (Filippi et al. 2009).

There are also disparities in the consequences of the various co-morbidities in terms of spermatogenic activity. Yamamoto et al. (1999) found decreased sperm concentration and motility, which resulted in significantly poorer IVF outcome in rabbits fed a highcholesterol diet for 12 weeks. Bataineh \& Nusier (2005), studying rats fed HFD for 60 days, confirmed the decrease in sperm quality and number which they attributed to be decreased seminiferous tubule diameter, decreased number of spermatocytes and spermatids and increased Leydig cell degeneration. Akagashi et al. (1997) found more extreme spermatogenic impairment in the form of atrophic seminiferous tubules devoid of spermatids in stroke-prone spontaneously hypertensive rats. Similar disturbances have not been reported neither for the other MetS contributors nor for the syndrome as a whole. The histological examination of the testes and epididymes of our HFD animals did not find any perturbations in cellular content or organisation. In the $\mathrm{HH}$ animals, there was evidence of disruptions reminiscent of those in the hypertensive rats; however, unlike the situation described by Akagashi et al. (1997), sperm were seen in the tubules and epididymes of our animals. Considering the duration of the study, this finding is consistent with the remnants of the last spermatogenic cycles prior to the treatment.

The influence of the individual elements of MetS on sperm quality appears to be similarly disparate. Studies on obese men (Kort et al. 2006, Chavarro et al. 2009) showed increased numbers of sperm with DNA fragmentation, findings that are partly corroborated by animal studies that have shown a small increase in sperm with nDNA damage (Bakos et al. 2011) and evidence of one of its consequences, decreased implantations (Ghanayem et al. 2010). This contrasts with the findings of our study, that showed no difference in the sperm nDNA status of either animal model. To our knowledge, no data exists on the effect of hypertension and/or dyslipidemia on sperm DNA integrity and the only report on $\mathrm{HH}$ found involved a very small number of human subjects and showed little difference (Smit et al. 2010).

One of the major causes of DNA damage in sperm is believed to be oxidative stress (Sakkas \& Alvarez 2010) and it is here that a possible explanation for the divergence in the findings of the various studies into MetS influence on sperm quality may be found. Oxidative stress is known to play an important role in various manifestations of MetS, but one that is thought to be only an early event in the pathology of what are chronic diseases (Roberts \& Sindhu 2009). In diabetes, there is evidence both in men (Agbaje et al. 2007) and in animal models, whether spontaneously occurring (O'Neill et al. 2009) or chemically induced diabetic mice (Shrilatha \& Muralidhara 2007a, O'Neill et al. 2009) and rats (Shrilatha \& Muralidhara 2007b), that the condition is associated with marked increases in oxidative stress and sperm nDNA damage. Hyperglycaemia is known to cause oxidative stress (Wautier \& Schmidt 2004, Chekir et al. 2006) and to accelerate the accumulation of advanced glycation end products and their receptor RAGE, both of which are capable of generating, promoting and/or amplifying oxidative stress and its detrimental consequences. It is this amplification and extension of the injurious oxidative environment that may be responsible for the damage seen in the previously mentioned studies. The proposition is supported by Bojesen et al. (2006) who concluded that in Klinefelter's syndrome it was the increased prevalence of diabetes (i.e. hyperglycaemia) rather than hypogonadism or the combination of conditions constituting MetS that is likely to play a role in jeopardising spermatogenesis. Interestingly there is no information provided as to the extent and level of glycaemia in the other mentioned studies. Although an increase in glucose was seen in our MetS and $\mathrm{HH}$ animals, it was modest, so the little evidence of CML and RAGE found in the reproductive tract and sperm of our animal models was not surprising. The minimal levels found may in turn explain the lack of difference in sperm nDNA integrity seen, as without their contribution an oxidative environment may not be established or adequately augmented to the extent necessary to cause damage.

We acknowledge that the full gamut and complexity of the co-morbidities that comprise the clinical manifestations of MetS are such that no experimental model will reflect, completely, the human situation. However, without the use of animal models, it is impossible to gain insights into the mechanisms responsible for the various pathologies that result from MetS. The model we describe has been shown to mimic many of the clinical manifestations of MetS and diabetes, particularly those associated with sexual and reproductive dysfunction (Filippi et al. 2009, Morelli et al. 2011, Vignozzi et al. 2011). As such, we believe that it more closely resembles the human condition and hence provides a useful means to investigate the mechanisms that undermine male reproductive function in MetS.

From our study, it can be concluded that although each of the contributing morbidities of MetS has an effect on spermatogenesis and sperm quality, it is probably the influence of glycation and its products that result from hyperglycaemia that is the most destructive. To be able to gain a further comparison, we plan to extend the duration of the HFD and thus investigate the chronic effects of the 
condition, namely the accumulation of weight (i.e. fat) and the increasing hyperglycaemic state. From this study, we have seen what the introduction of these changes causes to the reproductive tract, the planned studies will chronicle the development of the condition and thus provide insights into the mechanism(s) that undermine reproductive function in MetS.

\section{Materials and Methods}

\section{Animals}

All experiments were conducted with the approval of the Animal Care and Use committee of the University of Florence and in compliance with the Italian Ministerial Law \#116/92.

Male New Zealand white rabbits (Charles River, Calco, Lecco, Italy), initially weighing $\sim 3 \mathrm{~kg}$, were individually caged under standard conditions in a temperature and humidity controlled room on a $12 \mathrm{~h}$ light/12 $\mathrm{h}$ darkness cycle. Water and food were unrestricted throughout the study. After 1 week of standard rabbit diet, animals were randomly assigned to either control $(n=15)$ or treatment groups $(n=10)$. The control group continued to receive a standard diet (control), whereas the treatment group was fed a HFD constituted by $0.5 \%$ cholesterol and $4 \%$ peanut oil (HFD rabbit) for 12 weeks, according to a slightly modified previously described protocol (Azadzoi \& Saenz de Tejada 1991, Najibi et al. 1994). A subset of control rabbits was treated for the last 8 weeks with the long-acting GNRH analogue triptorelin pamoate (Ipsen, Milan, Italy, $2.9 \mathrm{mg} / \mathrm{kg}$ ), in order to induce a $\mathrm{HH}$, according to a previously described protocol (Filippi et al. 2002, Mancina et al. 2005).

Physical condition and body weight were measured at the onset of the study (baseline) and at the conclusion (12 weeks).

\section{Samples}

Blood for glucose, total cholesterol, triglycerides and Tanalyses was obtained from the animals via the marginal ear vein at week 0 (baseline) and at week 12 in all groups. The blood was immediately centrifuged at $2000 \mathrm{~g}$ for $20 \mathrm{~min}$, and the collected plasma stored at $-20{ }^{\circ} \mathrm{C}$ until assayed. Analyses was performed using standardised methods as described previously (Filippi et al. 2009).

Mean arterial blood pressure (MAP) was measured using a polyethylene catheter inserted into a femoral artery at week 12 , after pentobarbital $(45 \mathrm{mg} / \mathrm{kg}$ ) sedation. The rabbits were killed by a lethal dose of pentobarbital and seminal vesicles, testis, epididymides and lung harvested. All tissues collected were snap frozen, stored and then transported to Belfast for subsequent analyses.

One testis and epididymis from the animals in each group were thawed, immersed in Bouin's fixative and incubated for $4 \mathrm{~h}$ before being washed in several changes of $70 \%$ ethanol for a further $12-24 \mathrm{~h}$, then it is stored in absolute ethanol prior to embedding in paraffin wax using the standard procedure.

The remaining frozen epididymides were thawed in petri dishes containing PBS (Sigma-Aldrich) and milked using forceps to release stored sperm. Sperm were centrifuged at
$300 \mathrm{~g}$ for $10 \mathrm{~min}$, the supernatant was discarded, the pellet resuspended in PBS and centrifuged as before. After removal of the supernatant, the pellet was again resuspended in PBS, $0.1 \mathrm{ml}$ was removed to prepare smears for immunocytochemistry and the remainder was frozen in liquid nitrogen and stored until needed. Sperm smears were prepared on 3-aminopropyltriethoxysilane (APEs)-coated microscope slides, left to air dry, then fixed in absolute ethanol for $10 \mathrm{~min}$, air dried and stored until use.

\section{Histology}

Serial sections of $7 \mu \mathrm{m}$ for each sample were cut and placed on APEs-coated glass microscope slides. Tissue sections were dewaxed, rehydrated using a sequence of xylene, graded ethanol and water, then either washed in PBS and further processed for immunolocalisation (see following) or stained with periodic acid-Schiff's reagent and counterstained with haematoxylin using the standard procedure for microscopy examination.

\section{Immunolocalisation}

Antigens were unmasked by incubating the slides with a trypsin: PBS (1:1) solution for 2 min. After being washed briefly in PBS, the tissue was permeabilised and non-specific binding blocked by incubation in a combination of $0.1 \%$ Triton X-100 (Sigma-Aldrich) and $5 \%$ of either with donkey or goat serum at room temperature for $2 \mathrm{~h}$. Sections were then washed briefly in PBS before the addition of either primary goat anti-RAGE (R\&D Systems, Oxon, UK) or goat anti-CML antibody (Meridian Life Sciences, Saco, ME, USA) at 1/200 dilution in PBS with $0.1 \%$ Tween 20 or PBS (negative control) or goat/donkey lgG (isotype control; Zymed Laboratories, San Francisco, CA, USA). Sections were then incubated overnight in a humidified chamber at $4{ }^{\circ} \mathrm{C}$. The following day, samples were washed in PBS, incubated with a donkey anti-goat 488 fluor antibody (1:500; Invitrogen), washed again, mounted in Vectashield (Vector Laboratories, Burlingame, CA, USA) containing propidium iodide and coverslipped. All slides were examined and evaluated using a Nikon TE 2000 U confocal microscope.

\section{Protein extraction and quantitation}

Stored semen samples were thawed and aliquots of sperm were taken and centrifuged at $16000 \mathrm{~g}$ for $15 \mathrm{~min}$. Extraction buffer (500 $\mu \mathrm{l} ; 0.1 \%$ Triton X, $1 \%$ Tergitol, $0.1 \%$ SDS and $0.001 \%$ $\mathrm{NaN}_{3}$ ) in PBS was added and the pellet was homogenised on ice for $30 \mathrm{~s}$ using a hand-held mini pestle (Sigma-Aldrich). The resultant suspension was centrifuged at $10000 \mathrm{~g}$ for $10 \mathrm{~min}$ and the supernatant was collected. Protein content was determined using a bicinchoninic acid kit (Pierce BCATM Protein Assay Kit, Rockford, IL, USA) and microplate reader set at an absorbance of $562 \mathrm{~nm}$.

\section{ELISA}

CML immunoreactivity was quantified using a modification of the standard competitive ELISA protocol. Briefly, $200 \mu \mathrm{l}$ of 
$1 \mu \mathrm{g} / \mathrm{ml}$ AGE-BSA (Cambridge Biosciences, Cambridge, UK) in $0.05 \mathrm{~m}$ carbonate buffer ( $\mathrm{pH}$ 9.6) was added in each well of a 96-well plate (Nunc; Maxisorb, Roskilde, Denmark), covered and incubated at $4{ }^{\circ} \mathrm{C}$ overnight. Next day, the plates were washed in PBS wash buffer $\left(2 \mathrm{mM} \mathrm{KH_{2 }} \mathrm{PO}_{4}, 3 \mathrm{mM} \mathrm{NaCl}\right.$, $4.5 \mu \mathrm{M}$ 2,4-hexadienoic acid potassium salt, $0.001 \%$ Tween20 ), blocked ( $3 \%$ skimmed milk in $\mathrm{dd}_{2} \mathrm{O}$ for $2 \mathrm{~h}$ ), washed, samples and standards (triplicate wells of each) added, covered and incubated with 1:2000 dilution of 4G9, a previously validated (Virella et al. 2005) goat anti-CML antibody $(2 \mu \mathrm{g} / \mathrm{ml}$; Meridian Life Sciences) with gentle agitation for $2 \mathrm{~h}$. Standards of AGE-BSA in protein extraction buffer were serially diluted to give a range from 200 to $0.39 \mu$ g. Samples were diluted in a $0.05 \%$ Tween 20, $0.2 \%$ BSA and $75 \mathrm{~nm}$ PBS (pH 7.4) solution. A 1:5000 dilution of peroxidase-conjugated anti-mouse IgG was added, the plates were covered and incubated for $1 \mathrm{~h}$. Streptavidin-HRP $(100 \mu$ l of a 1:200 dilution) was added and the plates were placed out of direct light for $20 \mathrm{~min}$.

Levels of all forms of RAGE were measured using the DuoSet ELISA system (R\&D Systems), according to the manufacturer's protocol, all steps being performed at room temperature and out of direct light. Briefly, $100 \mu$ of RAGE capture antibody $(1 \mu \mathrm{g} / \mathrm{ml})$ was added per well of a 96 -well plate (Nunc; Maxisorb), covered and incubated at $4{ }^{\circ} \mathrm{C}$ overnight. Next day, the plates were washed with $0.05 \%$ Tween in PBS and then blocked with $1 \%$ BSA in PBS for $2 \mathrm{~h}$. Washed samples (equating to $100 \mu \mathrm{g}$ total protein) and standards (in triplicate) were diluted in reagent diluent (1\% BSA in PBS) and added, then the plate was covered and incubated with agitation for $2 \mathrm{~h}$. Standards of recombinant mouse RAGE in protein extraction buffer were serially diluted to give a range from $4000 \mathrm{pg} / \mathrm{ml}$ to $3.9 \mathrm{pg} / \mathrm{ml}$. After washing, $100 \mu \mathrm{l}$ biotinylated rat anti-mouse RAGE antibody $(100 \mathrm{ng} / \mathrm{ml})$ was added, the plates were covered and incubated for $2 \mathrm{~h}$, before further washing. In both analyses, streptavidin-HRP (100 $\mu$ l of a 1:200 dilution) was added and the plates were placed out of direct light for $20 \mathrm{~min}$.

For both the procedures, following a final washing step, 1:1 hydrogen peroxide-tetramethylbenzidine solution (Sigma-Aldrich) was added and the plates returned to the dark with gentle agitation for $20 \mathrm{~min}$. The colour reaction was stopped by the addition of $1 \mathrm{M} \mathrm{H}_{2} \mathrm{SO}_{4}$. The optical density of each well was measured using a Tecan Safire microplate reader (Tecan, Reading, UK) set to $450 \mathrm{~nm}$ and corrected by subtracting the reading obtained at $540 \mathrm{~nm}$. The concentration of CML or RAGE was determined using the appropriate standard curve and standardised according to the total protein initially added to each well.

\section{Acridine orange test}

Aliquots containing 2 million sperm were centrifuged (5000 g at $4{ }^{\circ} \mathrm{C}$ for $5 \mathrm{~min}$ ), the pellet resuspended in $100 \mu \mathrm{l}$ of TNE buffer $(0.15 \mathrm{M} \mathrm{NaCl}, 0.01 \mathrm{M}$ Tris, $1 \mathrm{mM}$ EDTA, pH 7.4) and transferred to a gauze-topped polypropylene tube prior to incubation in $0.4 \mathrm{ml}$ denaturing buffer $(0.17 \%$ Triton $\mathrm{X}, 0.15 \mathrm{M}$ $\mathrm{NaCl}, 0.08 \mathrm{~N} \mathrm{HCl}, \mathrm{pH} 1.20)$ for $30 \mathrm{~s}$. Staining buffer $(1.2 \mathrm{ml}$; $0.1 \mathrm{M}$ citric acid, $0.2 \mathrm{M} \mathrm{Na}_{2} \mathrm{HPO}_{4}, 1 \mathrm{mM}$ EDTA, $0.15 \mathrm{M} \mathrm{NaCl}$, $\mathrm{pH}$ 6.0) containing acridine orange $(6 \mathrm{mg} / \mathrm{ml})$ was added, briefly mixed and analysed by flow cytometry within 3-5 min of the addition of the stain. Sperm with normal (doublestranded) DNA fluoresce green and those with fragmented or single-stranded DNA fluoresce red.

\section{Statistical analysis}

Statistical analysis was performed using SPSS 11 for Microsoft Windows (SPSS, Inc., Chicago, IL, USA).

\section{Declaration of interest}

The authors declare that there is no conflict of interest that could be perceived as prejudicing the impartiality of the research reported.

\section{Funding}

This research did not receive any specific grant from any funding agency in the public, commercial or not-for-profit sector.

\section{Acknowledgements}

The authors thank our colleagues in the Centre for Vision Science, Queen's University of Belfast, for their advice and assistance. We gratefully acknowledge the financial support of the Fertility Research Trust.

\section{References}

Agbaje IM, Rogers DA, McVicar CM, McClure N, Atkinson AB, Mallidis C \& Lewis SE 2007 Insulin dependant diabetes mellitus: implications for male reproductive function. Human Reproduction 22 1871-1877. (doi:10.1093/humrep/dem077)

Aggerholm AS, Thulstrup AM, Toft G, Ramlau-Hansen CH \& Bonde JP 2008 Is overweight a risk factor for reduced semen quality and altered serum sex hormone profile? Fertility and Sterility 90 619-626. (doi:10. 1016/j.fertnstert.2007.07.1292)

Akagashi K, Kumamoto Y, Itoh N, Tsukamoto T, Suzuki T \& Ohta Y 1997 Manidipine improves spermatogenesis in the stroke-prone spontaneously hypertensive rat. Journal of Andrology 18 210-216.

Azadzoi KM \& Saenz de Tejada I 1991 Hypercholesterolemia impairs endothelium-dependent relaxation of rabbit corpus cavernosum smooth muscle. Journal of Urology 146 238-240.

Bakos HW, Mitchell M, Setchell BP \& Lane M 2011 The effect of paternal diet-induced obesity on sperm function and fertilization in a mouse model. International Journal of Andrology [in press]. (doi:10.1111/ j.1365-2605.2010.01092.x)

Bataineh HN \& Nusier MK 2005 Effect of cholesterol diet on reproductive function in male albino rats. Saudi Medical Journal $\mathbf{2 6}$ 398-404.

Ben-Sefer E, Ben-Natan M \& Ehrenfeld M 2009 Childhood obesity: current literature, policy and implications for practice. International Nursing Review 56 166-173. (doi:10.1111/j.1466-7657.2008.00 708.x)

Bojesen A, Kristensen K, Birkebaek NH, Fedder J, Mosekilde L, Bennett P, Laurberg P, Frystyk J, Flyvbjerg A, Christiansen JS et al. 2006 The metabolic syndrome is frequent in Klinefelter's syndrome and is associated with abdominal obesity and hypogonadism. Diabetes Care 29 1591-1598. (doi:10.2337/dc06-0145)

Breigeiron MK, Lucion AB \& Sanvitto GL 2007 Effects of renovascular hypertension on reproductive function in male rats. Life Sciences $\mathbf{8 0}$ 1627-1634. (doi:10.1016/j.Ifs.2007.01.030) 
Chavarro JE, Toth TL, Wright DL, Meeker JD \& Hauser R 2009 Body mass index in relation to semen quality, sperm DNA integrity, and serum reproductive hormone levels among men attending an infertility clinic. Fertility and Sterility 93 2222-2231. (doi:10.1016/j.fertnstert.2009. 01.100)

Chekir C, Nakatsuka M, Noguchi S, Konishi H, Kamada Y, Sasaki A, Hao L \& Hiramatsu Y 2006 Accumulation of advanced glycation end products in women with preeclampsia: possible involvement of placental oxidative and nitrative stress. Placenta 27 225-233. (doi:10.1016/j. placenta.2005.02.016)

Cornier MA, Dabelea D, Hernandez TL, Lindstrom RC, Steig AJ, Stob NR, Van Pelt RE, Wang H \& Eckel RH 2008 The metabolic syndrome. Endocrine Reviews 29 777-822. (doi:10.1210/er.2008-0024)

Corona G, Mannucci E, Forti G \& Maggi M 2009 Hypogonadism, ED, metabolic syndrome and obesity: a pathological link supporting cardiovascular diseases. International Journal of Andrology 32 587-598. (doi:10.1111/j.1365-2605.2008.00951.x)

Daniels SR, Jacobson MS, McCrindle BW, Eckel RH \& Sanner BM 2009 American Heart Association Childhood Obesity Research Summit Report. Circulation 119 e489-e517. (doi:10.1161/CIRCULATIONAHA. 109.192216)

Filippi S, Luconi M, Granchi S, Vignozzi L, Bettuzzi S, Tozzi P, Ledda F, Forti G \& Maggi M 2002 Estrogens, but not androgens, regulate expression and functional activity of oxytocin receptor in rabbit epididymis. Endocrinology 143 4271-4280. (doi:10.1210/en.2002220384)

Filippi S, Vignozzi L, Morelli A, Chavalmane A, Sarchielli E, Fibbi B, Saad F, Sandner P, Ruggiano P, Vannelli G et al. 2009 Testosterone partially ameliorates metabolic profile and erectile responsiveness to PDE5 inhibitors in an animal model of male metabolic syndrome. Journal of Sexual Medicine 6 3274-3288. (doi:10.1111/j.1743-6109. 2009.01467.x)

Fouchecourt S, Metayer S, Locatelli A, Dacheux F \& Dacheux JL 2000 Stallion epididymal fluid proteome: qualitative and quantitative characterization; secretion and dynamic changes of major proteins. Biology of Reproduction 62 1790-1803. (doi:10.1095/biolreprod62.6. 1790)

Ghanayem BI, Bai R, Kissling GE, Travlos G \& Hoffler U 2010 Diet-induced obesity in male mice is associated with reduced fertility and potentiation of acrylamide-induced reproductive toxicity. Biology of Reproduction 82 96-104. (doi:10.1095/biolreprod.109.078915)

Gould DC, Amoroso P \& Kirby RS 2006 Hypoandrogen-metabolic syndrome: a significant issue for men's health. BJU International 98 494-496. (doi:10.1111/j.1464-410X.2006.06291.x)

Hammoud AO, Gibson M, Peterson CM, Meikle AW \& Carrell DT 2008a Impact of male obesity on infertility: a critical review of the current literature. Fertility and Sterility 90 897-904. (doi:10.1016/j.fertnstert. 2008.08.026)

Hammoud AO, Wilde N, Gibson M, Parks A, Carrell DT \& Meikle AW $2008 b$ Male obesity and alteration in sperm parameters. Fertility and Sterility 90 2222-2225. (doi:10.1016/j.fertnstert.2007.10.011)

Handelsman DJ, Conway AJ, Boylan LM, Yue DK \& Turtle JR 1985 Testicular function and glycemic control in diabetic men. A controlled study. Andrologia 17 488-496. (doi:10.1111/j.1439-0272.1985. tb01047.x)

Henkel R, Kierspel E, Hajimohammad M, Stalf T, Hoogendijk C, Mehnert C, Menkveld R, Schill WB \& Kruger TF 2003 DNA fragmentation of spermatozoa and assisted reproduction technology. Reproductive Biomedicine Online 7 477-484. (doi:10.1016/S14726483(10)61893-7)

Jensen TK, Andersson AM, Jorgensen N, Andersen AG, Carlsen E, Petersen JH \& Skakkebaek NE 2004 Body mass index in relation to semen quality and reproductive hormones among 1,558 Danish men. Fertility and Sterility 82 863-870. (doi:10.1016/j.fertnstert.2004. 03.056)

Kasturi SS, Tannir J \& Brannigan RE 2008 The metabolic syndrome and male infertility. Journal of Andrology 29 251-259. (doi:10.2164/jandrol. 107.003731)

Kort HI, Massey JB, Elsner CW, Mitchell-Leef D, Shapiro DB, Witt MA \& Roudebush WE 2006 Impact of body mass index values on sperm quantity and quality. Journal of Andrology 27 450-452. (doi:10.2164/ jandrol.05124)
MacDonald AA, Herbison GP, Showell M \& Farquhar CM 2010 The impact of body mass index on semen parameters and reproductive hormones in human males: a systematic review with meta-analysis. Human Reproduction Update 16 293-311. (doi:10.1093/humupd/ dmp047)

Mallidis C, Agbaje I, Rogers D, Glenn J, McCullough S, Atkinson AB, Steger K, Stitt A \& McClure N 2007 Distribution of the receptor for advanced glycation end products in the human male reproductive tract: prevalence in men with diabetes mellitus. Human Reproduction 22 2169-2177. (doi:10.1093/humrep/dem156)

Mallidis C, Agbaje IM, Rogers DA, Glenn JV, Pringle R, Atkinson AB, Steger K, Stitt AW \& McClure N 2009 Advanced glycation end products accumulate in the reproductive tract of men with diabetes. International Journal of Andrology 32 295-305. (doi:10.1111/j.1365-2605.2007. 00849.x)

Mancina R, Filippi S, Marini M, Morelli A, Vignozzi L, Salonia A, Montorsi F, Mondaini N, Vannelli GB, Donati S et al. 2005 Expression and functional activity of phosphodiesterase type 5 in human and rabbit vas deferens. Molecular Human Reproduction 11 107-115. (doi:10. 1093/molehr/gah143)

Meyer J, Koro CE \& L'Italien GJ 2005 The metabolic syndrome and schizophrenia: a review. International Review of Psychiatry 17 173-180. (doi:10.1080/09540260500071798)

Morelli A, Vignozzi L, Maggi M \& Adorini L 2011 Farnesoid X receptor activation improves erectile dysfunction in models of metabolic syndrome and diabetes. Biochimica et Biophysica Acta [in press]. (doi:10.1016/j.bbadis.2010.10.013)

Morris ID, Ilott S, Dixon L \& Brison DR 2002 The spectrum of DNA damage in human sperm assessed by single cell gel electrophoresis (Comet assay) and its relationship to fertilization and embryo development. Human Reproduction 17 990-998. (doi:10.1093/humrep/17.4.990)

Najibi S, Cowan CL, Palacino JJ \& Cohen RA 1994 Enhanced role of potassium channels in relaxations to acetylcholine in hypercholesterolemic rabbit carotid artery. American Journal of Physiology $\mathbf{2 6 6}$ H2061-H2067.

Nguyen RH, Wilcox AJ, Skjaerven R \& Baird DD 2007 Men's body mass index and infertility. Human Reproduction 22 2488-2493. (doi:10.1093/ humrep/dem139)

Niven MJ, Hitman GA \& Badenoch DF 1995 A study of spermatozoal motility in type 1 diabetes mellitus. Diabetic Medicine 12 921-924. (doi:10.1111/j.1464-5491.1995.tb00397.x)

O'Neill J, Czerwiec A, Agbaje I, Glenn J, Stitt A, McClure N \& Mallidis C 2009 Differences in mouse models of diabetes mellitus in studies of male reproduction. International Journal of Andrology 33 709-716. (doi:10. 1111/j.1365-2605.2009.01013.x)

Ramlau-Hansen CH, Thulstrup AM, Nohr EA, Bonde JP, Sorensen TI \& Olsen J 2007 Subfecundity in overweight and obese couples. Human Reproduction 22 1634-1637. (doi:10.1093/humrep/dem035)

Roberts CK \& Sindhu KK 2009 Oxidative stress and metabolic syndrome. Life Sciences 84 705-712. (doi:10.1016/j.Ifs.2009.02.026)

Sakkas D \& Alvarez JG 2010 Sperm DNA fragmentation: mechanisms of origin, impact on reproductive outcome, and analysis. Fertility and Sterility 93 1027-1036. (doi:10.1016/j.fertnstert.2009.10.046)

Sallmen M, Sandler DP, Hoppin JA, Blair A \& Baird DD 2006 Reduced fertility among overweight and obese men. Epidemiology 17 520-523. (doi:10.1097/01.ede.0000229953.76862.e5)

Shabsigh R, Arver S, Channer KS, Eardley I, Fabbri A, Gooren L, Heufelder A, Jones H, Meryn S \& Zitzmann M 2008 The triad of erectile dysfunction, hypogonadism and the metabolic syndrome. International Journal of Clinical Practice 62 791-798. (doi:10.1111/j.1742-1241. 2008.01696.x)

Sharpe RM 2010 Environmental/lifestyle effects on spermatogenesis. Philosophical Transactions of the Royal Society of London. Series B, Biological Sciences 365 1697-1712. (doi:10.1098/rstb.2009.0206)

Shrilatha B \& Muralidhara 2007a Early oxidative stress in testis and epididymal sperm in streptozotocin-induced diabetic mice: its progression and genotoxic consequences. Reproductive Toxicology 23 578-587. (doi:10.1016/j.reprotox.2007.02.001)

Shrilatha B \& Muralidhara 2007 b Occurrence of oxidative impairments, response of antioxidant defences and associated biochemical 
perturbations in male reproductive milieu in the Streptozotocin-diabetic rat. International Journal of Andrology 30 508-518. (doi:10.1111/j.13652605.2007.00748.x)

Smit M, Romijn JC, Wildhagen MF, Weber RF \& Dohle GR 2010 Sperm chromatin structure is associated with the quality of spermatogenesis in infertile patients. Fertility and Sterility 94 1748-1752. (doi:10.1016/ j.fertnstert.2009.10.030)

Swierstra EE \& Foote RH 1965 Duration of spermatogenesis and spermatozoan transport in the rabbit based on cytological changes, DNA synthesis and labeling with tritiated thymidine. American Journal of Anatomy 116 401-412. (doi:10.1002/aja.1001160206)

Vernet P, Aitken RJ \& Drevet JR 2004 Antioxidant strategies in the epididymis. Molecular and Cellular Endocrinology 216 31-39. (doi:10. 1016/j.mce.2003.10.069)

Vignon F, Le Faou A, Montagnon D, Pradignac A, Cranz C, Winiszewsky P \& Pinget M 1991 Comparative study of semen in diabetic and healthy men. Diabetes \& Metabolism 17 350-354.

Vignozzi L, Morelli A, Filippi S, Comeglio P, Chavalmane AK, Marchetta M, Toce M, Yehiely-Cohen R, Vannelli GB, Adorini L et al. 2011 Farnesoid X receptor activation improves erectile function in animal models of metabolic syndrome and diabetes. Journal of Sexual Medicine 8 57-77. (doi:10.1111/j.1743-6109.2010.02073.x)
Virella G, Derrick MB, Pate V, Chassereau C, Thorpe SR \& Lopes-Virella MF 2005 Development of capture assays for different modifications of human low-density lipoprotein. Clinical and Diagnostic Laboratory Immunology 12 68-75. (doi:10.1128/CDLI.12.1.68-75.2005)

Vlassara H \& Palace MR 2002 Diabetes and advanced glycation endproducts. Journal of Internal Medicine 251 87-101. (doi:10.1046/j.13652796.2002.00932.x)

Wautier JL \& Schmidt AM 2004 Protein glycation: a firm link to endothelial cell dysfunction. Circulation Research 95 233-238. (doi:10.1161/01. RES.0000137876.28454.64)

Yamamoto Y, Shimamoto K, Sofikitis N \& Miyagawa I 1999 Effects of hypercholesterolaemia on Leydig and Sertoli cell secretory function and the overall sperm fertilizing capacity in the rabbit. Human Reproduction 14 1516-1521. (doi:10.1093/humrep/14.6.1516)

Received 19 November 2010

First decision 5 January 2011

Revised manuscript received 23 March 2011

Accepted 4 April 2011 